\title{
Origins of the Excessive Westward Extension of ENSO SST Simulated in CMIP5 and CMIP6 Models 0
}

\author{
WenPing Jiang, ${ }^{\mathrm{a}, \mathrm{b}}$ Ping HuAng, ${ }^{\mathrm{b}, \mathrm{c}}$ GANG HuAng, ${ }^{\mathrm{b}, \mathrm{d}}$ AND Jun Ying ${ }^{\mathrm{e}, \mathrm{f}}$ \\ ${ }^{\text {a }}$ Key Laboratory of Marine Hazards Forecasting, Ministry of Natural Resources/College of Oceanography, Hohai University, \\ Nanjing, China \\ ${ }^{\mathrm{b}}$ State Key Laboratory of Numerical Modeling for Atmospheric Sciences and Geophysical Fluid Dynamics, Institute of Atmospheric \\ Physics, Chinese Academy of Sciences, Beijing, China \\ ${ }^{\mathrm{c}}$ Center for Monsoon System Research, Institute of Atmospheric Physics, Chinese Academy of Sciences, Beijing, China \\ ${ }^{\mathrm{d}}$ University of Chinese Academy of Sciences, Beijing, China \\ ${ }^{\text {e }}$ State Key Laboratory of Satellite Ocean Environment Dynamics, Second Institute of Oceanography, Ministry of Natural Resources, \\ Hangzhou, China \\ ${ }^{\mathrm{f}}$ Southern Marine Science and Engineering Guangdong Laboratory (Zhuhai), Zhuhai, China
}

(Manuscript received 15 July 2020, in final form 23 December 2020)

\begin{abstract}
An excessive westward extension of the simulated ENSO-related sea surface temperature (ENSO SST) variability in the CMIP5 and CMIP6 models is the most apparent ENSO SST pattern bias and dominates the intermodel spread in ENSO SST variability among the models. The ENSO SST bias lowers the models' skill in ENSO-related simulations and induces large intermodel uncertainty in ENSO-related projections. The present study investigates the origins of the excessive westward extension of ENSO SST in 25 CMIP5 and 25 CMIP6 models. Based on the intermodel spread of ENSO SST variability simulated in the 50 models, we reveal that this ENSO SST bias among the models largely depends on the simulated cold tongue strength in the equatorial western Pacific (EWP). Models simulating a stronger cold tongue tend to simulate a larger mean zonal SST gradient in the EWP and then a larger zonal advection feedback in the EWP, favoring a more westward extension of the ENSO SST pattern. In addition, with the overall improvement in the EWP cold tongue from CMIP5 to CMIP6, the excessive westward extension bias of ENSO SST in CMIP6 models is also reduced relative to those in CMIP5 models. The results suggest that the bias and intermodel disagreement in the mean-state SST have been improved, which improves ENSO simulation.
\end{abstract}

KEYWORDS: ENSO; Model comparison; Model errors; Model evaluation/performance

\section{Introduction}

El Niño-Southern Oscillation (ENSO), which originates from ocean-atmosphere interaction in the tropical Pacific (Rasmusson and Carpenter 1982), is the largest climate signal on interannual time scales. The ENSO-related sea surface temperature (SST) variability (hereafter referred to simply as "ENSO SST variability"; Power et al. 2013; Huang and Xie 2015; Cai et al. 2018) not only affects the tropical climate but also exerts profound impacts on extratropical weather and climate through atmospheric teleconnections (Horel and Wallace 1982; Ropelewski and Halpert 1987; Lau and Nath 1996).

Coupled general circulation models (CGCMs) are effective tools for understanding and projecting ENSO and its global teleconnections. The performance of CGCMs in reproducing ENSO's observed behaviors is crucial for determining the reliability of the models' projections of future climate change. However, there are still some common biases in simulating ENSO SST variability, despite the fact that models that

Supplemental information related to this paper is available at the Journals Online website: https://doi.org/10.1175/JCLI-D-200551.s1.

Corresponding authors: Dr. Ping Huang, huangping@mail.iap. ac.cn; Dr. Wenping Jiang, jiangwenping@hhu.edu.cn participated in phase 5 of the Coupled Model Intercomparison Project (CMIP5) performed better than the previous iteration (Guilyardi et al. 2012; Kim and Yu 2012; Kug et al. 2012; Bellenger et al. 2014; Kim et al. 2014; Yeh et al. 2014). The well-known bias of the simulated ENSO SST variability is the excessive westward extension of ENSO SST variability into the western Pacific compared to observation (Fig. 1) (Collins et al. 2010; Kim and Yu 2012; Kug et al. 2012; Chowdary et al. 2014). Moreover, this excessive westward extension of ENSO SST variability still exists in most of the CGCMs participating in the latest phase of CMIP (i.e., CMIP6) (Fig. 1d).

The excessive westward extension of ENSO SST variability can influence the simulation performance and forecasting skill of coupled models in many aspects (Gong et al. 2015; Jiang et al. 2017; Tao et al. 2018; Li et al. 2019). For instance, corresponding to the westward extension of the ENSO SST variability, the positive precipitation anomalies and atmospheric circulation anomalies also shift too far west (Misra et al. 2007; Ham and Kug 2015), increasing local convective activity in the tropical western Pacific. Meanwhile, the subtle SST variations in the tropical western Pacific warm pool have large impacts on the location and intensity of atmospheric response as well as ENSO's teleconnections (Spencer and Slingo 2003; Gong et al. 2015). In addition, coupled models with a relatively larger excessive westward extension of ENSO SST variability have a lower seasonal forecasting skill on the SST anomaly in the western Pacific (Ham et al. 2014). 

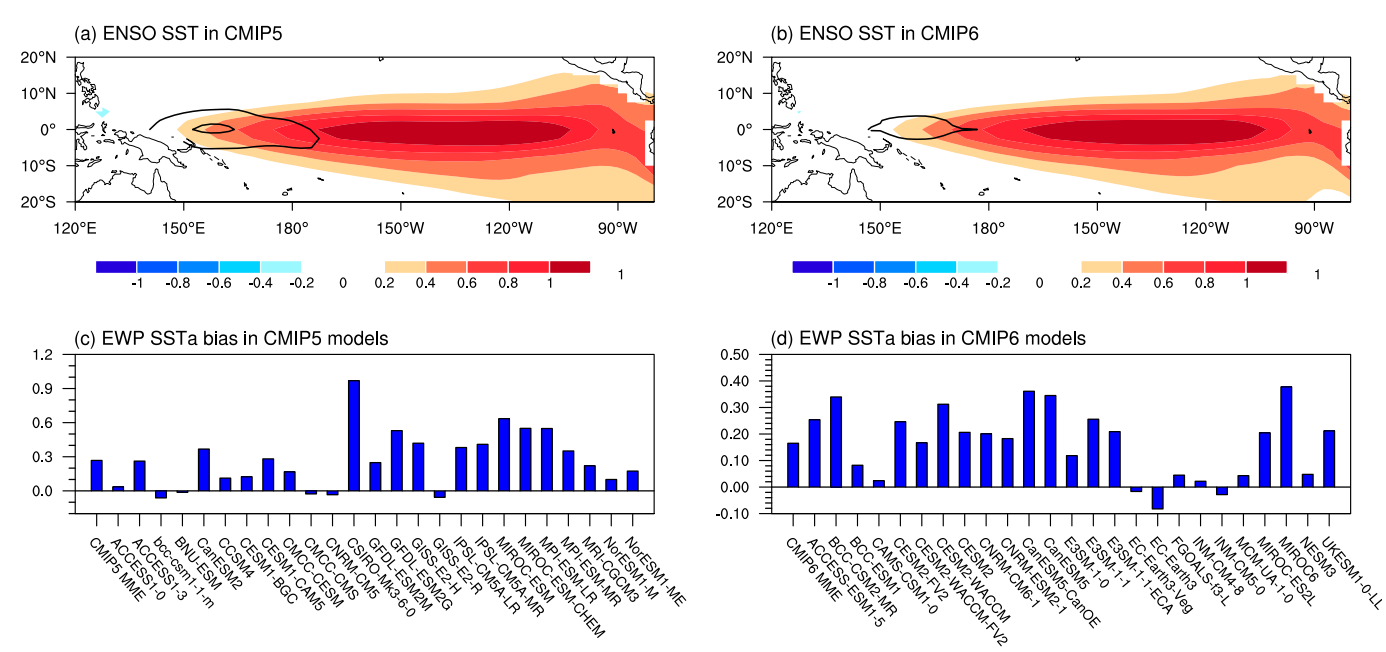

FIG. 1. (top) ENSO-related SST anomalies (shaded) and their biases (contours; the black lines denote +0.2 and $+0.4 \mathrm{~K}$ ) in (a) CMIP5 MME and (b) CMIP6 MME. (bottom) ENSO-related SST anomaly bias in the EWP $\left(5^{\circ} \mathrm{S}-\right.$ $\left.5^{\circ} \mathrm{N}, 140^{\circ} \mathrm{E}-180^{\circ}\right)$ in (c) CMIP5 models and (d) CMIP6 models.

The simulation of ENSO's behaviors largely depends on the simulation of the mean state (Kug et al. 2012; Ham and Kug 2014, 2015; Jiang et al. 2017; Li et al. 2019). Many state-of-theart climate models suffer from an overly strong and westward extended cold tongue (CT) in the equatorial Pacific ( $\mathrm{Li}$ and $\mathrm{Xie}$ 2012; Zheng et al. 2012; Li and Xie 2014). Previous studies have suggested that the excessive equatorial Pacific CT bias could limit the skill of models in simulating ENSO characteristics (Guilyardi et al. 2009; Graham et al. 2017; Jiang et al. 2017; Ferrett et al. 2018; Bayr et al. 2019a). Specifically, the CT bias could lead to a westward shift of the rising branch of the Walker circulation, which in turn leads to a too westward convection response during ENSO events (Latif and Keenlyside 2009; Bayr et al. 2018, 2019b). Moreover, most CGCMs with a large CT bias tend to underestimate the positive wind-SST feedback and the negative shortwave feedback. The error compensation between the two feedbacks hampers the simulation of ENSO asymmetry and ENSO phase locking (Guilyardi et al. 2009; Kim et al. 2014; Bayr et al. 2018, 2019b). In addition, the CT bias also disturbs ENSO projections under global warming (Collins et al. 2010; Cai et al. 2015; Jiang et al. 2020). Recently, Jiang et al. (2020) suggested that models with a stronger cold tongue bias tend to project more frequent central Pacific El Niño. However, the connection between the excessive CT bias and the excessive westward extension of ENSO SST has not been clearly identified, and the underlying mechanism yet to be elucidated.

The present study determines that the excessive westward extension of ENSO SST variability is the most apparent bias of ENSO SST by utilizing an intermodel empirical orthogonal function (EOF) analysis, and reveals its solid linkage with the overly strong CT based on their intermodel spread in the CMIP5 and CMIP6 models. We identify the zonal advection feedback as a key process connecting the CT strength and ENSO SST intensity in the EWP in CMIP5 and CMIP6 models. Moreover, the excessive westward extension of ENSO SST is reduced in CMIP6 compared to that in CMIP5 due to the improved simulation of the EWP CT simulation in CMIP6 models. The rest of the paper is organized as follows. Section 2 is a brief description of the model datasets and methods used in this study. Section 3 investigates the leading intermodel spread pattern of ENSO SST bias and its origins in CMIP5 and CMIP6 models in terms of intermodel diversity. Section 4 compares the multimodel ensemble (MME) biases in the CMIP5 and CMIP6 models. Section 5 provides a summary.

\section{Data and methods}

\section{a. Models and observations}

The monthly mean outputs of the historical run from 25 CMIP5 models (Taylor et al. 2012) and 25 CMIP6 models (Eyring et al. 2016) are used in this study. Table 1 lists the model names. We only analyzed the first realization (r1i1p1 for CMIP5 and r1i1p1f1 for CMIP6) of each model. The monthly mean SST, ocean potential temperature, and ocean zonal current from 1961 to 2000 are used. For comparing with observations, we also use the observational monthly mean SST data from the Extended Reconstructed SST, version 3 (ERSST.v3). All the model outputs and observational datasets are interpolated onto the same $2.5^{\circ} \times 2.5^{\circ}$ grid before analysis.

\section{b. ENSO SST}

To extract the ENSO SST variability, the linear trend and the annual cycle are first removed from the historical runs, and then the unstandardized Niño-3.4 index [defined as the December-February (DJF) SST anomalies averaged over the region $5^{\circ} \mathrm{S}-5^{\circ} \mathrm{N}, 120^{\circ}-170^{\circ} \mathrm{W}$ ] is regressed onto the interannual anomalies of SST to display the ENSO SST variability. The regression on the unstandardized Niño-3.4 index excludes the effect of ENSO amplitude, with only the structural changes in the ENSO-related variability retained. Our focus is on boreal winter (DJF), which is the typical peak season for ENSO. 
(a) EOF1

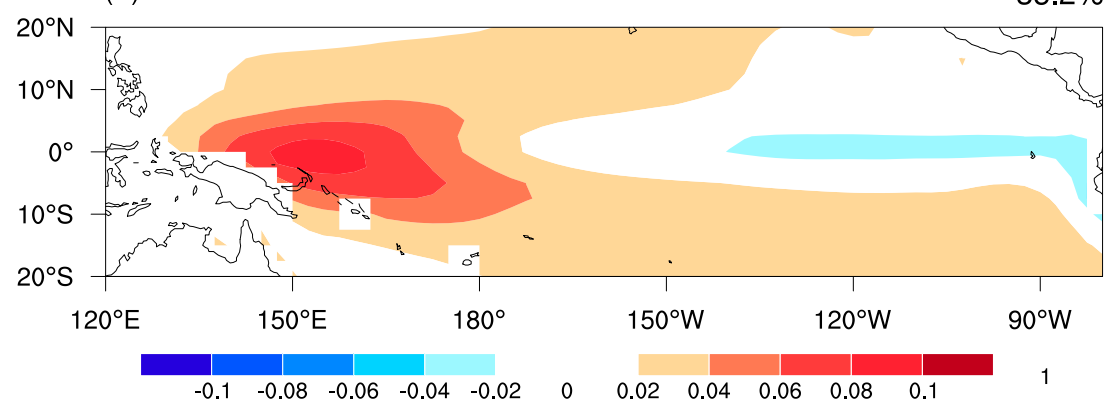

(b) Intermodel regression onto CT index
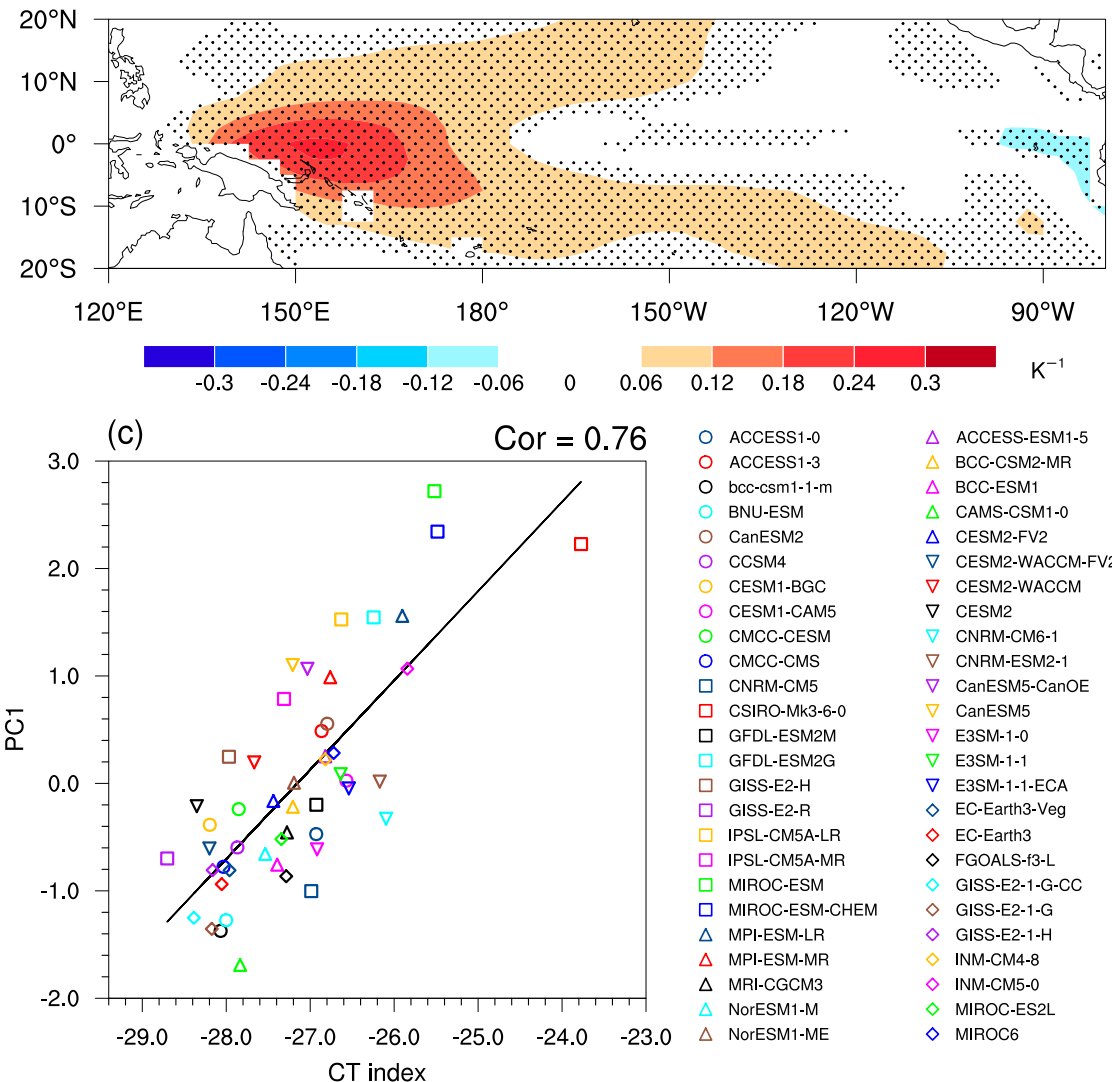

FIG. 2. (a) First EOF eigenvector of intermodel differences (deviation of the individual models' response from the MME) in the ENSO SST. (b) Intermodel regression of ENSO SST bias onto CT index. (c) Relationship between PC1 and CT index in the 50 models. The intermodel correlation coefficient is shown in the top right of the panel and is significant at the $99 \%$ confidence level, based on the Student's $t$ test. Stippling in (b) indicates the regressions are significant at the $95 \%$ confidence level, based on the Student's $t$ test.

Unless stated otherwise in the text, all results are for the winter season only.

\section{c. Zonal advection feedback}

The zonal advection feedback is defined by the anomalous zonal advection of the mean zonal SST gradient as $-u^{\prime} \partial \bar{T} / \partial x$, where $u^{\prime}$ represents the zonal current anomaly and $\bar{T}$ denotes the climatological upper ocean temperature. The mixed layer depth is chosen as a constant of $50 \mathrm{~m}$ (Dwyer et al. 2012). To shed light on the effect of the CT bias on the zonal advection feedback, we decompose the zonal advection feedback into two components:

$$
-\left(u^{\prime} \frac{\partial \bar{T}}{\partial x}\right)_{r}=-u_{m}^{\prime} \frac{\partial \bar{T}}{\partial x_{r}}-u_{r}^{\prime} \frac{\partial \bar{T}}{\partial x_{m}},
$$


TABLE 1. The 25 CMIP5 and 25 CMIP6 models used in this study.

\begin{tabular}{lcc}
\hline & CMIP5 & CMIP6 \\
\hline 1 & ACCESS1.0 & ACCESS-ESM1-5 \\
2 & ACCESS1.3 & BCC-CSM2-MR \\
3 & BCC-CSM1.1-m & BCC-ESM1 \\
4 & BNU-ESM & CAMS-CSM1-0 \\
5 & CanESM2 & CESM2-FV2 \\
6 & CCSM4 & CESM2-WACCM-FV2 \\
7 & CESM1-BGC & CESM2-WACCM \\
8 & CESM1-CAM5 & CESM2 \\
9 & CMCC-CESM & CNRM-CM6-1 \\
10 & CMCC-CMS & CNRM-ESM2-1 \\
11 & CNRM-CM5 & CanESM5-CanOE \\
12 & CSIRO-Mk3.6.0 & CanESM5 \\
13 & GFDL-ESM2G & E3SM-1-0 \\
14 & GFDL-ESM2M & E3SM-1-1 \\
15 & GISS-E2-H & E3SM-1-1-ECA \\
16 & GISS-E2-R & EC-Earth3-Veg \\
17 & IPSL-CM5A-LR & EC-Earth3 \\
18 & IPSL-CM5A-MR & FGOALS-f3-L \\
19 & MIROC-ESM & GISS-E2-1-G-CC \\
20 & MIROC-ESM-CHEM & GISS-E2-1-G \\
21 & MPI-ESM-LR & GISS-E2-1-H \\
22 & MPI-ESM-MR & HadGEM3-GC31-LL \\
23 & MRI-CGCM3 & IPSL-CM6A-LR \\
24 & NorESM1-M & MIROC-ES2L \\
25 & NorESM1-ME & MIROC6 \\
\hline & &
\end{tabular}

in which the subscript $r$ represents the intermodel regression upon the CT index, and the subscript $m$ represents the MME. This Eq. (1) follows the Newton-Leibniz formula.

\section{Linkage between the excessive CT and ENSO SST variability}

Figures 1a and 1b show the ENSO SST variability and their biases in the CMIP5 MME and the CMIP6 MME, respectively. The two generations of CGCMs can roughly simulate the ENSO characteristics of conspicuous SST anomalies in the central and eastern Pacific. However, there still exists a wellknown systematic bias-the excessive westward extension of ENSO SST variability-clearly appearing both in the CMIP5 MME and CMIP6 MME. Specifically, the ENSO SST bias mainly dominates in the EWP around $5^{\circ} \mathrm{S}-5^{\circ} \mathrm{N}, 140^{\circ} \mathrm{E}-180^{\circ}$. The averaged ENSO SST bias in the EWP in individual models is shown for CMIP5 and CMIP6 in Figs. 1c and 1d, respectively. Although the strength of ENSO SST bias varies from model to model, most models simulate a pronounced overly strong bias in the EWP. In contrast, a small number of models can simulate realistic ENSO SST, and even an overly weak SST bias in the EWP (such as BCC-CSM1.1-m and GISS-E2-R in CMIP5, and EC-Earth3 and INM-CM5-0 in CMIP6) (Figs. 1c,d).

Utilizing the intermodel diversity in ENSO SST bias, we perform an intermodel EOF analysis for the 50 CMIP5/6 models on the simulated ENSO SST variability in the tropical Pacific $\left(20^{\circ} \mathrm{S}-20^{\circ} \mathrm{N}, 120^{\circ}-80^{\circ} \mathrm{W}\right)$. The first mode of the intermodel EOF explains $35.2 \%$ of the total variance of the intermodel spread of the simulated ENSO SST variability. Figure 2a shows the first EOF eigenvector of intermodel differences in the simulated ENSO SST. The EOF pattern exhibits a horseshoe pattern with a positive center in the EWP, indicating that the excessive westward extension of ENSO SST variability dominates the intermodel spread in the simulated ENSO SST variability.

To elucidate the effect of the excessive mean-state CT bias on the simulation of the ENSO SST pattern, we calculate the intermodel regression of the ENSO SST pattern onto a CT index to represent the CT strength, defined as the mean-state SST averaged over the CT region $\left(2^{\circ} \mathrm{S}-2^{\circ} \mathrm{N}, 150^{\circ} \mathrm{E}-140^{\circ} \mathrm{W}\right)$ in the historical run multiplied by -1 . The multiplication by -1 is used to produce a larger CT index value to denote a stronger CT. The CT index regressed ENSO SST pattern (Fig. 2b) is very similar to the leading intermodel mode in the simulated ENSO SST (Fig. 2a). Moreover, the standardized first principal component (PC1) is highly correlated with the CT strength, with a high intermodel correlation of 0.76 , exceeding the $99 \%$ confidence level based on the Student's $t$ test (Fig. 2c). This result indicates that the simulated CT strength is the leading source of the intermodel spread of ENSO SST variability.

The development of ENSO events is primarily related to three feedbacks: the zonal advection feedback, the thermocline feedback, and the Ekman pumping feedback (Li 1997; Jin et al. 2006). The thermocline feedback and the Ekman pumping feedback can be expressed as $-\bar{\omega} \partial T^{\prime} / \partial z$, and $-\omega^{\prime} \partial \bar{T} / \partial z$, respectively, where $\bar{\omega}$ and $\omega^{\prime}$ represent the climatological and anomalous upwelling respectively, and $T^{\prime}$ and $\bar{T}$ denote the anomalous and climatological upper-ocean temperature, respectively. Considering that the thermocline is thick in the EWP and the vertical temperature gradient is small in mixed layer, we can omit the contribution of the thermocline feedback and the Ekman pumping feedback may be negligible. Figure S1 in the online supplemental material verifies that the two feedbacks make a slight negative contribution to the excessive westward extension of ENSO SST variability.

Previous studies have suggested that the CT bias potentially influences the simulation and projection of ENSO SST in the EWP through modifying the zonal advection feedback process. Graham et al. (2017) indicated that the excessive CT contributes to a warm peak of ENSO SST in the western Pacific largely due to the unrealistic zonal advection feedback in CMIP5 models. Jiang et al. (2020) also found that the excessive CT can change the mean-state SST warming pattern and lead to unrealistic changes in ENSO SST variability in the EWP through modifying zonal advection feedback. Thus, to investigate the mechanisms by which the CT bias leads to the ENSO SST bias, we calculate the intermodel regression of the zonal advection feedback onto the CT index among the 50 CGCMs. The regressed zonal advection feedback (Fig. 3a) is significantly positive in the EWP, similar to the intermodel regressed ENSO SST pattern shown in Fig. 2b, which means the zonal advection feedback should be the key process for the excessive westward extension of ENSO SST variability influenced by the excessive CT bias. As shown in Eq. (1), the zonal advection feedback related to CT strength can be decomposed into two terms, $-u_{m}^{\prime} \partial \bar{T} / \partial x_{r}$ and $-u_{r}^{\prime} \partial \bar{T} / \partial x_{m}$, related to the intermodel spreads 


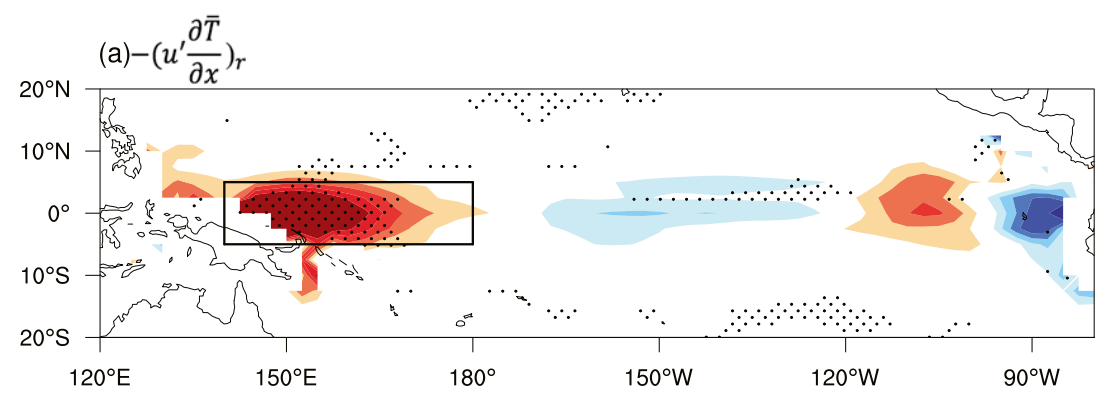

(b) $-u_{\mathrm{m}}^{\prime} \cdot \frac{\partial \bar{T}}{\partial x_{r}}$
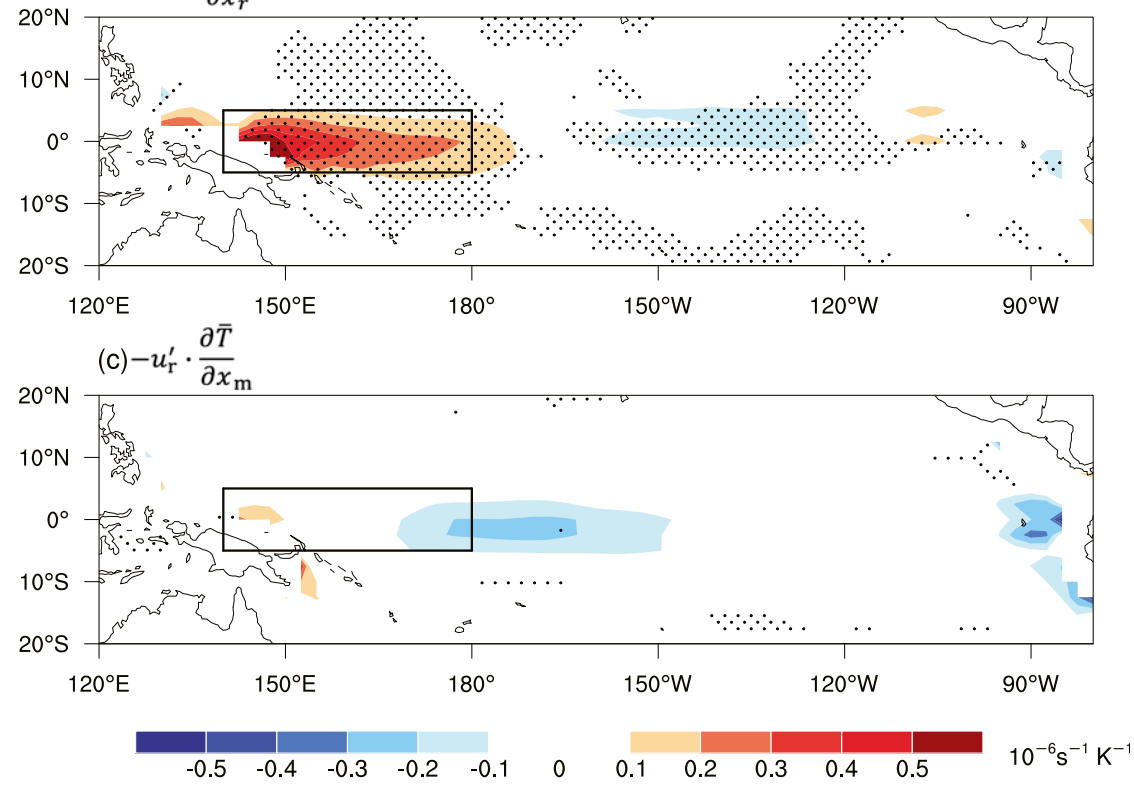

FIG. 3. (a) Intermodel regression of zonal advection feedback onto the CT index. (b) Intermodel regression of the mean zonal SST gradient multiplied by the MME of the ENSO-related zonal current anomaly. (c) Intermodel regression of the ENSO-related zonal current anomaly multiplied by the MME of the mean zonal SST gradient. Stippling indicates that regressions are significant at the $95 \%$ confidence level.

in the zonal gradient of the mean-state SST and ENSO-related zonal oceanic current, respectively. Comparing Figs. $3 \mathrm{~b}$ and $3 \mathrm{c}$ for $-u_{m}^{\prime} \partial \bar{T} / \partial x_{r}$ and $-u_{r}^{\prime} \partial \bar{T} / \partial x_{m}$, respectively, we can conclude that the term $-u_{m}^{\prime} \partial \bar{T} / \partial x_{r}$ is mainly responsible for the positive signal in the EWP of the zonal advection feedback related to CT strength (Figs. 3b,c), while the term $-u_{r}^{\prime} \partial \bar{T} / \partial x_{m}$ contributes little to the excessive westward extension of ENSO SST variability.

The spatial patterns of $-u_{m}^{\prime} \partial \bar{T} / \partial x_{r}$ (Fig. 3b) are dominated by the intermodel spread in the zonal SST gradient related to CT strength $\left(-\partial \bar{T} / \partial x_{r}\right)$ (Fig. 4a). The connection between the zonal SST gradient and CT strength shown in Fig. 4a concurs with the previous conclusion that the models with a stronger CT tend to simulate a larger west-minus-east mean zonal SST gradient in the EWP (Graham et al. 2017; Jiang et al. 2017). Furthermore, the positive zonal SST gradient in the EWP and the ENSO-related eastward current anomalies in the equatorial Pacific $\left(u_{m}^{\prime} ;\right.$ Fig. $\left.4 \mathrm{~b}\right)$ generate a positive zonal advection feedback in the EWP (Fig. 3a), which plays an important role in developing the larger ENSO SST variability in the EWP. Meanwhile, the ENSO-related eastward current anomalies ( $u_{m}^{\prime}$; Fig. 4b) may be related with the prevailing ENSOrelated westerly wind anomalies and convective anomalies over the equatorial Pacific (Fig. S2).

The above linkage from the simulated CT strength in the EWP, the zonal SST gradient, and the zonal advection feedback to the ENSO SST variability in the EWP are also reorganized in the individual CMIP5 and CMIP6 models (Fig. 5). The CT index is significantly correlated with the simulated ENSO SST in the EWP (Fig. 5a), with an intermodel correlation coefficient among the 50 CGCMs of 0.73 , consistent with the widely significant regression in Fig. $2 \mathrm{~b}$. In this linkage, a stronger CT would induce a larger zonal SST gradient in the EWP (Fig. 5b, correlation coefficient 0.82 ), then a more conspicuous zonal advection feedback in the EWP (Fig. 5c; correlation coefficient 0.64 ), and finally a stronger SST variability in the EWP (Fig. 5d; correlation coefficient 0.71). 


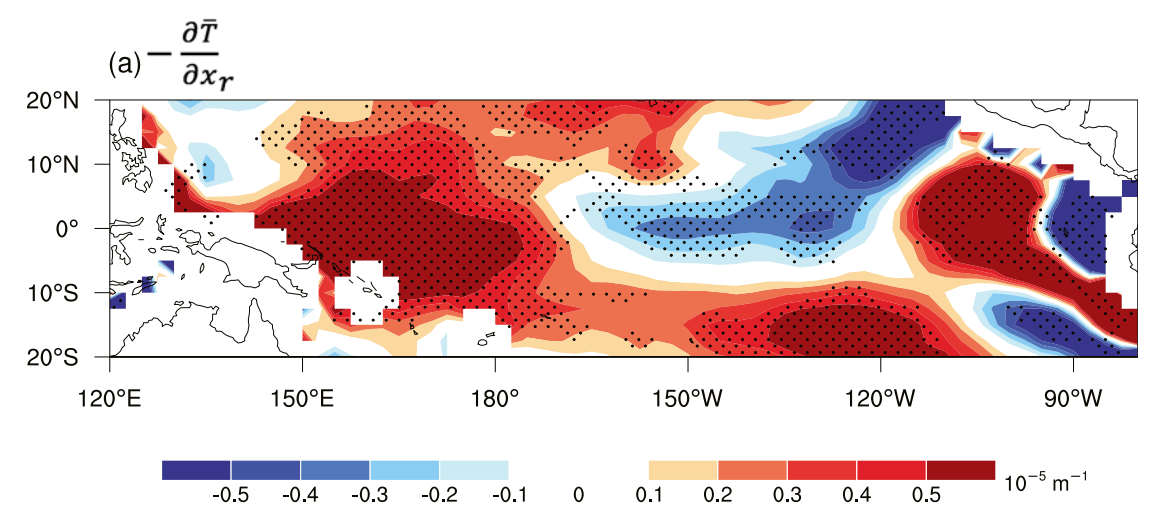

(b) $u_{m}^{\prime}$

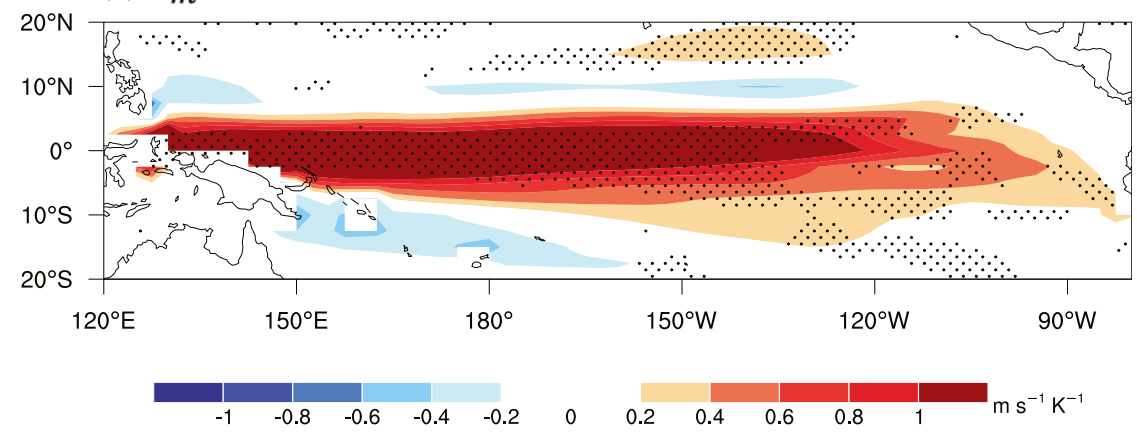

FIG. 4. (a) Intermodel regression of the mean zonal SST gradient onto the CT index. (b) MME of the ENSO-related zonal current anomaly. Stippling in (a) indicates that regressions are significant at the $95 \%$ confidence level. Stippling in (b) indicates the regions where the sign of the MME agrees in more than $68 \%$ of models.

It is worth noting that the model CSIRO-Mk3.6.0 (in the top right of each panel in Fig. 5) is a remarkable outlier compared to the other 49 models. We also calculate the intermodel correlation coefficients of the other 49 models for the pairs in Fig. 5, revealing correlation coefficients of $0.63,0.77,0.49$, and 0.52 , respectively. All of them also exceed the $99 \%$ confidence level based on the Student's $t$ test, suggesting that the result from CSIRO-Mk3.6.0 does not influence our conclusions.

In general, the heat flux feedbacks during the developing stage of ENSO are usually treated as a damping factor to balance the positive contribution from oceanic dynamic feedbacks (Jin et al. 2006; Chen et al. 2016). However, most CGCMs underestimate the heat flux feedback (Sun et al. 2003; Lloyd et al. 2011; Bellenger et al. 2014; Li et al. 2015), and those models with a large CT bias tend to have weaker heat flux feedbacks (Bayr et al. 2018, 2019b), which may favor ENSO SST developing. Thus, we investigate the effects of heat flux feedback related to CT strength on the simulation of ENSO SST. Figure 6 shows the intermodel regression of the net heat flux feedback (measured by the regression coefficient between the net heat flux anomalies at the surface and Niño-3.4 index; Li et al. 2015) and its components against the CT index. A positive net heat flux feedback related to CT strength dominates in the equatorial Pacific, indicating that models with a strong CT tend to have weaker negative effects of net heat flux, which are beneficial to ENSO SST developing in the equatorial Pacific. This result is consistent with previous studies (Bayr et al. 2018, 2019b).

Moreover, the underestimated net heat flux feedback due to the CT bias mainly comes from shortwave feedback (Fig. 6). However, the strongest underestimation of the CT bias-related shortwave feedback is located in the central Pacific, east to the key area of the westward extension of ENSO SST variability (black boxes in Fig. 6), possibly because that the convection in the equatorial central Pacific with local SST near the convective threshold is more sensitive to the mean-state SST than in the EWP. Figure 7a provides the relationship between the shortwave feedback in the EWP $\left(5^{\circ} \mathrm{S}-5^{\circ} \mathrm{N}, 140^{\circ} \mathrm{E}-180^{\circ}\right)$ and $\mathrm{CT}$ index in 50 models and 49 models, the correlation coefficients do not exceed the $99 \%$ confidence level. Moreover, the relationship between the shortwave feedback in the EWP and the EWP SST anomalies is also weak (Fig. 7b), which suggests that the contribution of the CT bias-related shortwave feedback to the excessive westward extension of ENSO SST is negligible. In addition, considering that the atmospheric circulation could be closer to a relative SST (Johnson and Xie 2010; Izumo et al. 2019), we also defined a relative CT index by climatological SST averaged over the CT region $\left(2^{\circ} \mathrm{S}-2^{\circ} \mathrm{N}, 150^{\circ} \mathrm{E}-140^{\circ} \mathrm{W}\right)$ subtracting the tropical Pacific mean SST $\left(30^{\circ} \mathrm{S}-30^{\circ} \mathrm{N}, 120^{\circ} \mathrm{E}-\right.$ $\left.100^{\circ} \mathrm{W}\right)$, and analyzed the relationship between the shortwave 

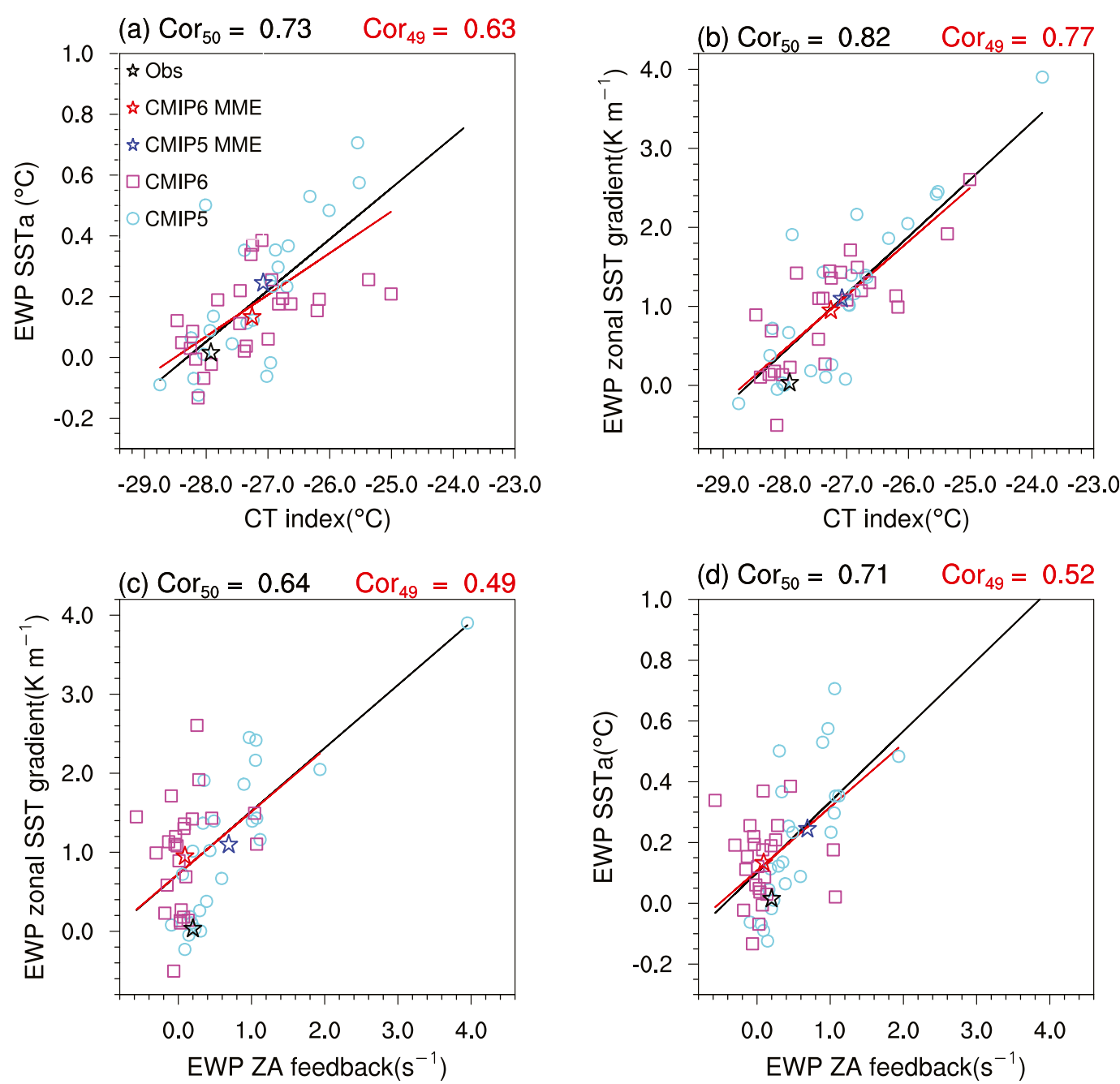

FIG. 5. (top) Scatterplots of the CT index vs (a) the simulated EWP SST anomaly $\left(5^{\circ} \mathrm{S}-5^{\circ} \mathrm{N}, 140^{\circ} \mathrm{E}-180^{\circ}\right)$ and (b) the EWP mean zonal SST gradient $\left(5^{\circ} \mathrm{S}-5^{\circ} \mathrm{N}, 140^{\circ} \mathrm{E}-180^{\circ}\right)$ in 50 models. (bottom) Scatterplots of the EWP zonal advection feedback $\left(5^{\circ} \mathrm{S}-5^{\circ} \mathrm{N}, 140^{\circ} \mathrm{E}-180^{\circ}\right)$ vs (c) the EWP mean zonal SST gradient and (d) the EWP SST anomaly in 50 models. Black lines denote the linear fit of 50 models, and red lines denote the linear fit of 49 models (excluding the CSIRO-Mk3.6.0 from all 50 models). The intermodel correlation coefficients of the 50 models ( 49 models) are shown in the top left (top right) of the panels. All correlation coefficients are significant at the $99 \%$ confidence level, based on the Student's $t$ test.

feedback in the EWP and the relative CT index in 50 models and 49 models. Although the correlation coefficients of the shortwave feedback and the relative CT index are a little bit higher than those in Fig. 7a (0.37 for 50 models and 0.25 for 49 models), the relative CT bias-related shortwave feedback is also negligible for the excessive westward extension of ENSO SST (not shown).

\section{Comparison of ENSO SST in CMIP5 and CMIP6}

The MME result in Figs. 1a and 1b for CMIP5 and CMIP6, respectively, shows that the simulation skill with respect to the ENSO SST pattern has been improved in CMIP6 relative to that in CMIP5. Moreover, Fig. 5 also shows this improvement can be found in each physical node from the CT strength to ENSO SST pattern in CMIP6 MME. Figures $1 \mathrm{a}$ and $1 \mathrm{~b}$ compare the ENSO SST pattern between the CMIP6 MME and the CMIP5 MME. Although the excessive westward extension of ENSO SST bias still exists in the CMIP6 MME, the degree of the westward extension of ENSO SST in the CMIP6 MME has been apparently reduced (Figs. 1 and 5).

The improvement of ENSO SST variability simulated in CMIP6 from the improvement of the simulated CT can be clearly seen in the spatial patterns. Figure 8 shows the spatial patterns of the mean-state SST bias in the CMIP5 MME and the CMIP6 MME, and their difference. There is a cold SST bias in the equatorial western-central Pacific (i.e., 
(a) $\left(Q_{n e t}\right)_{r}$

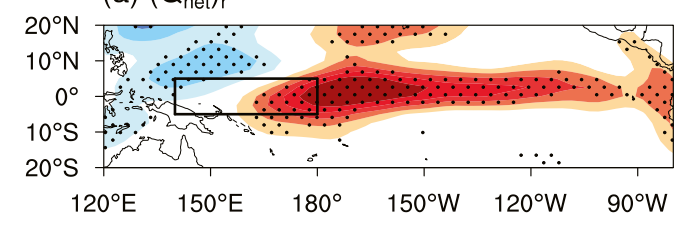

(b) $\left(Q_{\mathrm{LH}}\right)_{\mathrm{r}}$

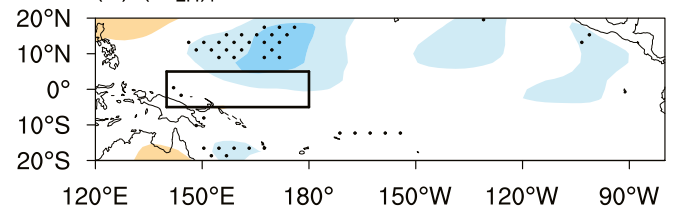

(d) $\left(Q_{S w}\right)_{r}$

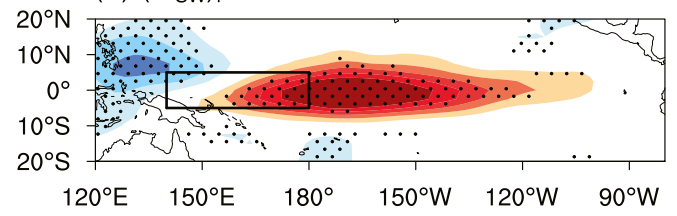

(c) $\left(Q_{S H}\right)_{r}$

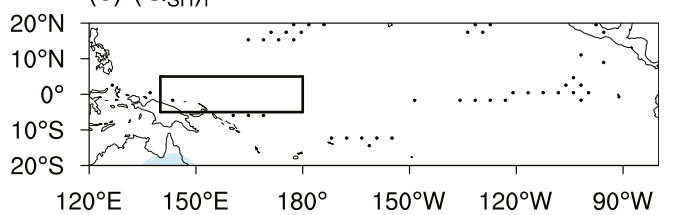

(e) $\left(\mathrm{Q}_{\mathrm{L} W}\right)_{\mathrm{r}}$
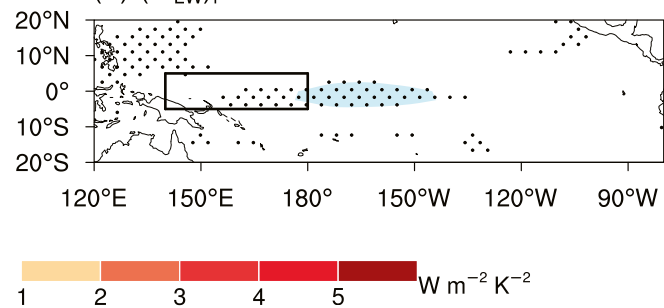

FIG. 6. Intermodel regression of the ENSO-related heat flux (positive downward) onto the CT index: (a) net heat flux, (b) latent heat flux, (c) sensible heat flux, (d) shortwave radiation, and (e) longwave radiation. Stippling indicates that regressions are significant at the $95 \%$ confidence level. Black boxes highlight the key area of the excessive westward extension of ENSO SST in the EWP region.

the excessive CT bias), with a center at around $180^{\circ}$ and a warm SST bias in the southeastern Pacific both in the CMIP5 and CMIP6 MME (Figs. 8a,b). However, the strength of the cold SST bias and its intermodel spread in the equatorial western-central Pacific is significantly improved in the CMIP6 MME (Fig. 8c). Moreover, Figs. 9a-c compare the spatial patterns of the simulated mean zonal
SST gradient bias in the CMIP5 and CMIP6 MME. The mean-state SST bias gets colder and then gets warmer from west to east in the equatorial western-central Pacific (Figs. 8a,b), leading to a "positive west-negative east", mean zonal SST gradient bias in the CMIP5 MME and the CMIP6 MME (Figs. 9a,b). Like the improved mean-state SST bias in the CMIP6 MME (Fig. 8c), the mean zonal SST
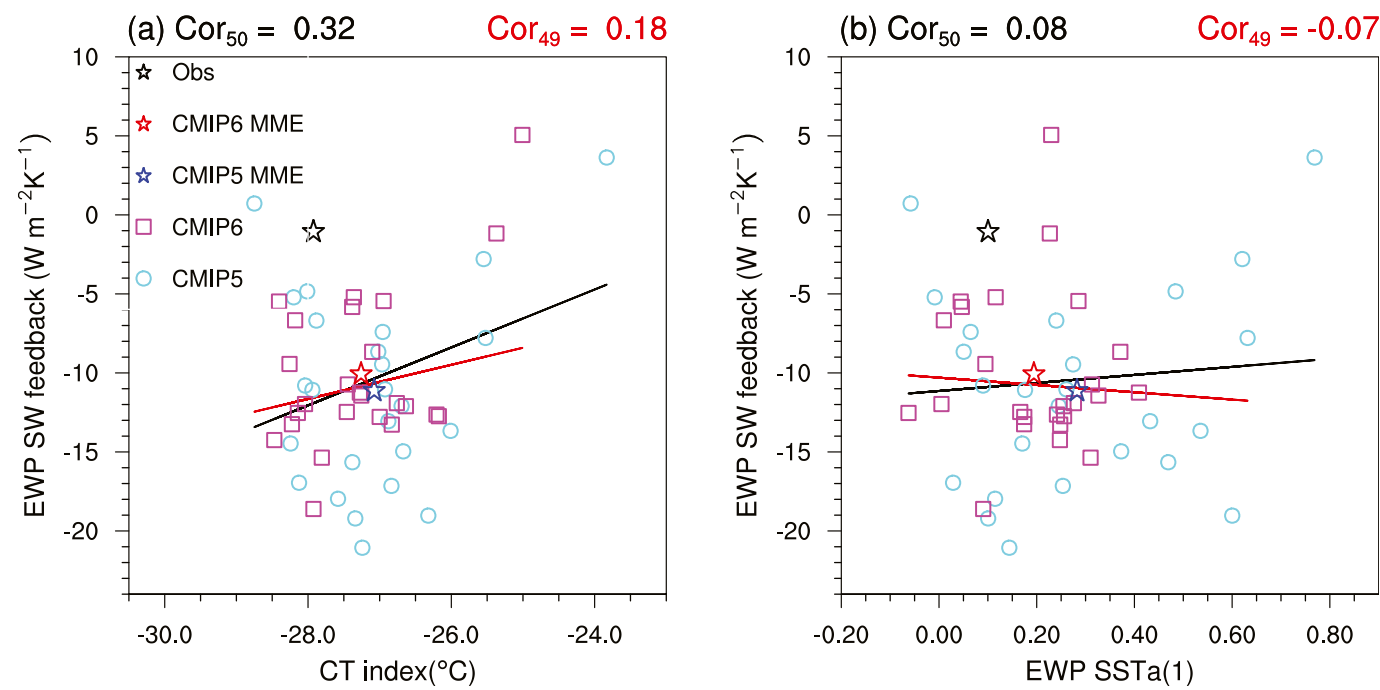

FIG. 7. Scatterplots of the shortwave feedback around $5^{\circ} \mathrm{S}-5^{\circ} \mathrm{N}, 140^{\circ} \mathrm{E}-180^{\circ}$ vs (a) CT index and (b) the EWP SST anomalies $\left(5^{\circ} \mathrm{S}-5^{\circ} \mathrm{N}, 140^{\circ} \mathrm{E}-180^{\circ}\right)$ in 50 models (black lines) and 49 models (red lines). The intermodel correlation coefficients of the 50 models ( 49 models) are shown in the top left (top right) of the panels. 
(a) Clim SST bias in CMIP5

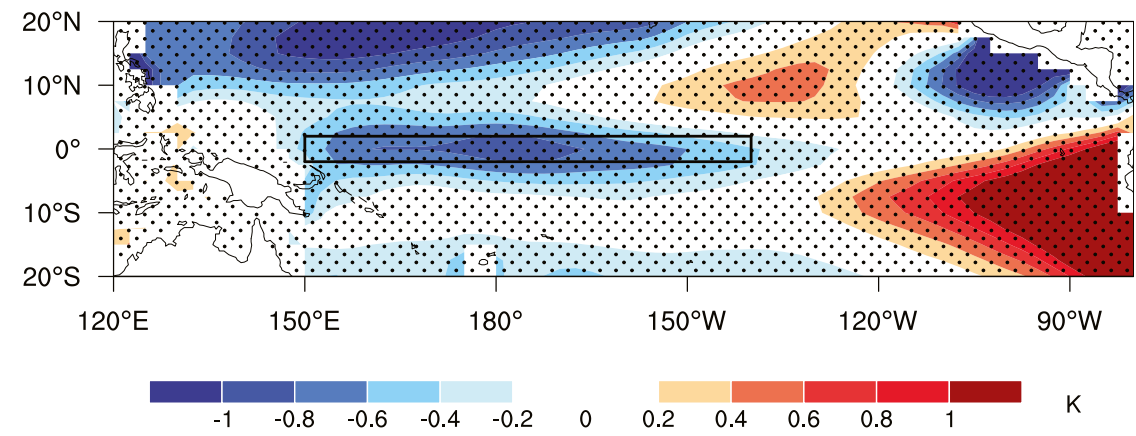

(b) Clim SST bias in CMIP6

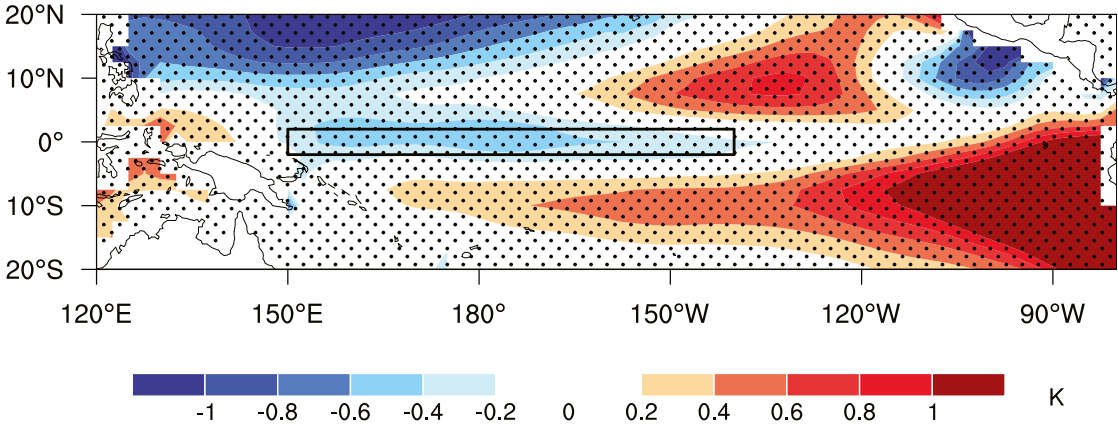

(c) $b-a$

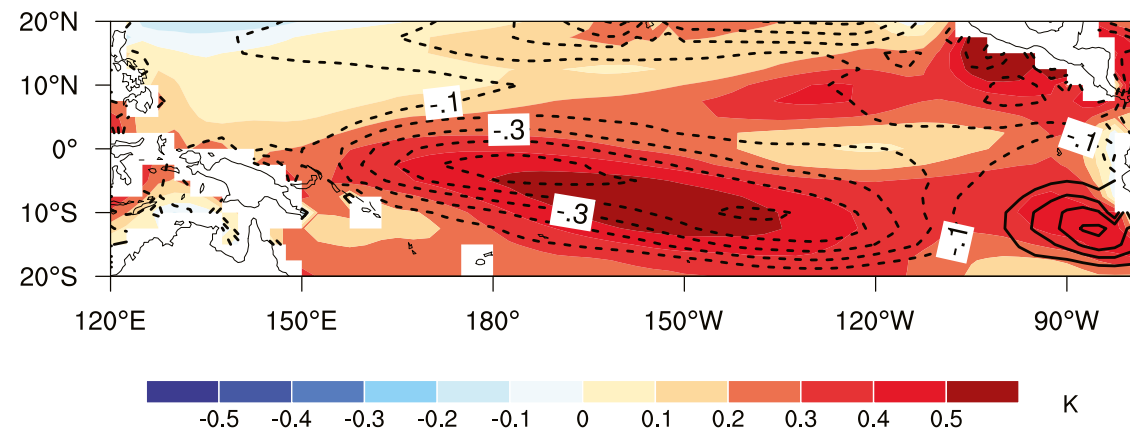

FIG. 8. (a) SST mean-state bias in the MME of 25 CMIP5 models. (b) As in (a), but for the MME of 25 CMIP6 models. (c) Difference between (b) and (a) (shading), and the difference of their intermodel standard deviation between CMIP6 models and CMIP5 models (contours; black lines denote values from -0.5 to 0.5 with intervals of 0.1 , and dashed lines denote negative values). Stippling in (a) and (b) indicates the regions where the sign of the MME agrees in more than $68 \%$ of models. The black boxes in (a) and (b) highlight the region for defining the CT index.

gradient bias in both poles of the dipole pattern is also reduced in CMIP6 in comparison to CMIP5 (Fig. 9c).

By comparing the two generations of models, the large-value center of zonal advection feedback simulated in the CMIP6 MME is situated more eastward than that in CMIP5 MME (Figs. 10a,b), leading to a "negative west-positive east" dipole pattern of their difference in the equatorial Pacific (Fig. 10c), which should be responsible for the improvement in simulating the ENSO SST in the EWP in the CMIP6 MME (Fig. 7c). The spatial pattern difference of the zonal advection feedback is dominated by the difference in the mean zonal SST gradient (Fig. 9c), which ultimately comes from the improved SST mean state (Fig. 8c).

\section{Summary and discussion}

This paper investigates the origins of the most remarkable bias in ENSO SST pattern bias, the excessive westward extension of ENSO SST variability, in state-of-the-art models (25 CMIP5 models and 25 CMIP6 models). The degree of 
(a) Zonal SST gradient bias in CMIP5

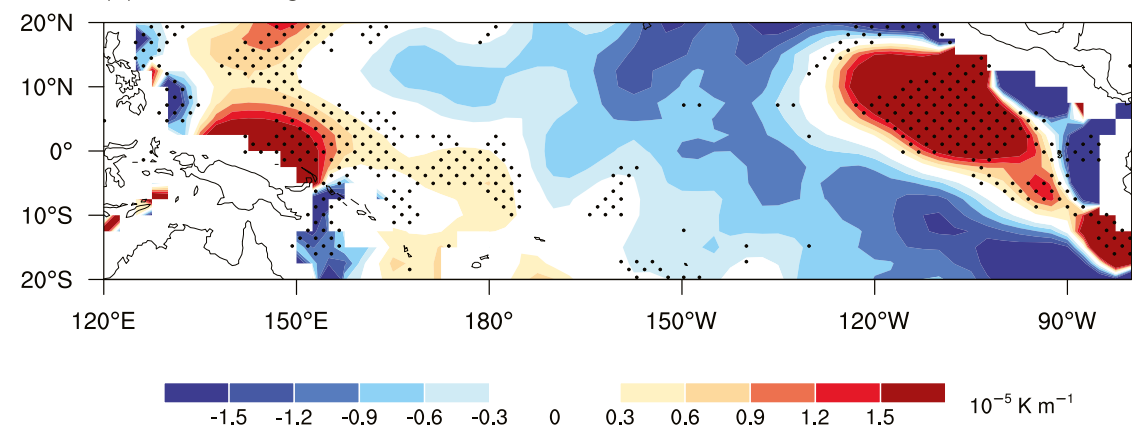

(b) Zonal SST gradient bias in CMIP6

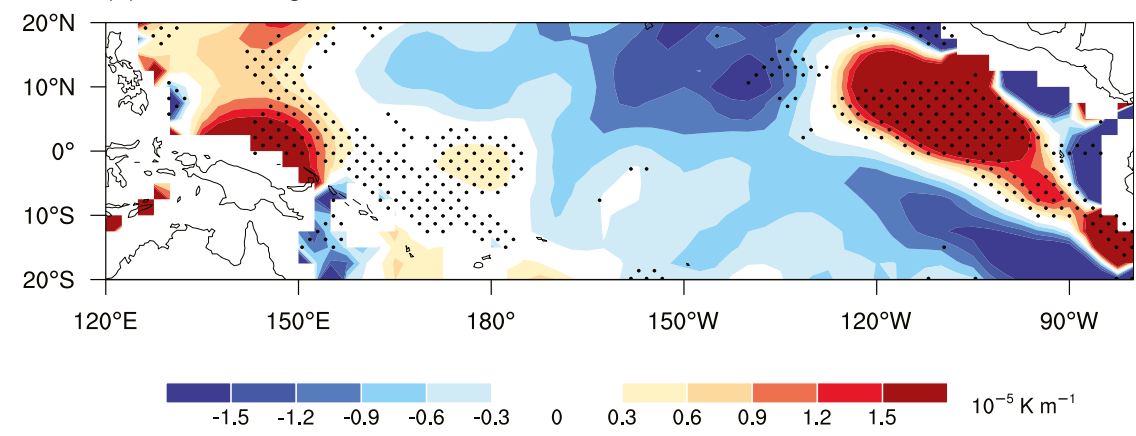

(c) $b-a$

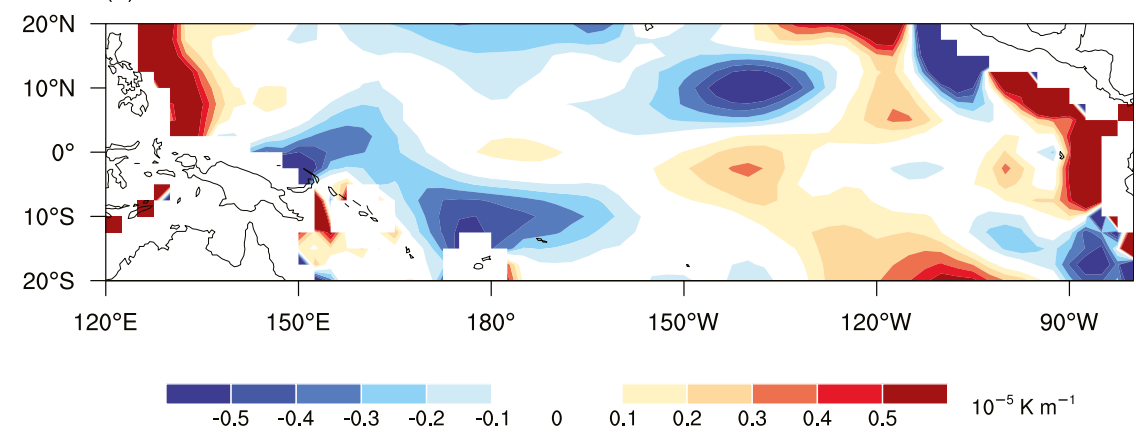

FIG. 9. (a) Mean zonal SST gradient bias in the MME of 25 CMIP5 models. (b) As in (a), but for the MME of 25 CMIP6 models. (c) Difference between (b) and (a). Stippling in (a) and (b) indicates the regions where the sign of the MME agrees in more than $68 \%$ of models.

excessive westward extension of ENSO SST variability also dominates the intermodel spread in ENSO SST variability among the CMIP5 and CMIP6 models. Based on the intermodel spread of ENSO SST, we identify that the excessive westward extension of ENSO SST bias is closely related to another long-standing system bias: the excessive CT. Specifically, a model with a stronger CT tends to simulate a stronger ENSO SST variability in the EWP in CMIP5 and CMIP6 models. In the CT-ENSO SST linkage, a stronger $\mathrm{CT}$ in the tropical Pacific favors a stronger zonal SST gradient in the EWP and then a stronger zonal advection feedback under the effects of the ENSO-related zonal current, which ultimately contributes to a stronger SST variability in the EWP.
Comparing the performances of CMIP5 and CMIP6 models, it is found that the simulation of ENSO SST bias has been commonly improved in the latest CMIP6 models, with a less excessive westward extension bias. As expected, the improvement of ENSO SST bias in the CMIP6 models can be traced back to the improvement in the degree of the westward extension of the CT bias simulated in CMIP6. This result demonstrates the importance of the simulated mean state to the simulation of ENSO, and indicates that more attention should be given to understanding and improving the simulation of the mean-state SST in climate models.

The excessive CT bias is a common problem in current CGCMs and its origin is still under debate, including too strong trade winds (Guilyardi et al. 2009), biases in the convection 
(a) ZA feedback bias in CMIP5

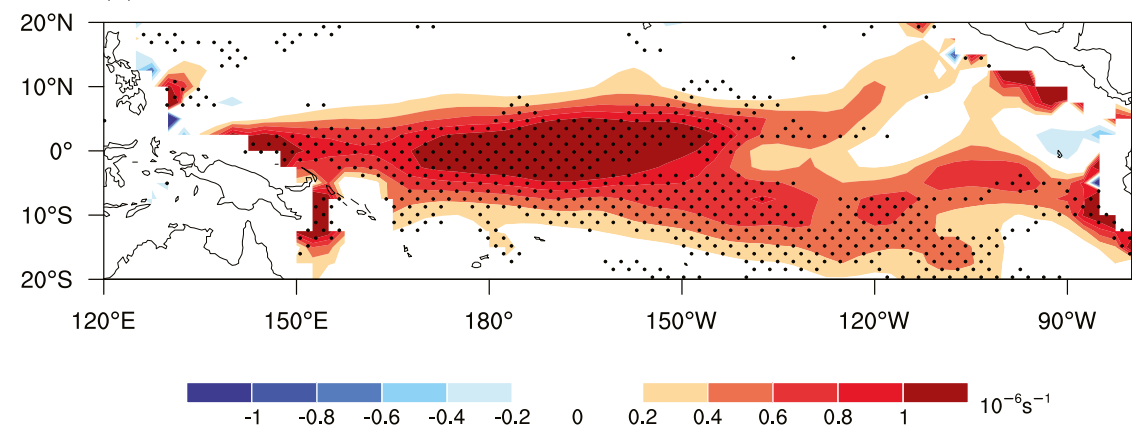

(b) ZA feedback bias in CMIP6

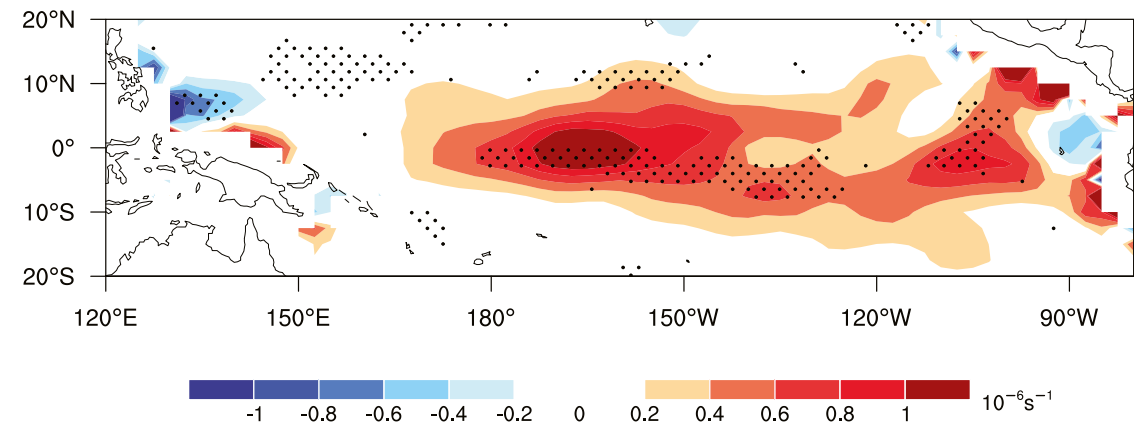

(c) $b-a$

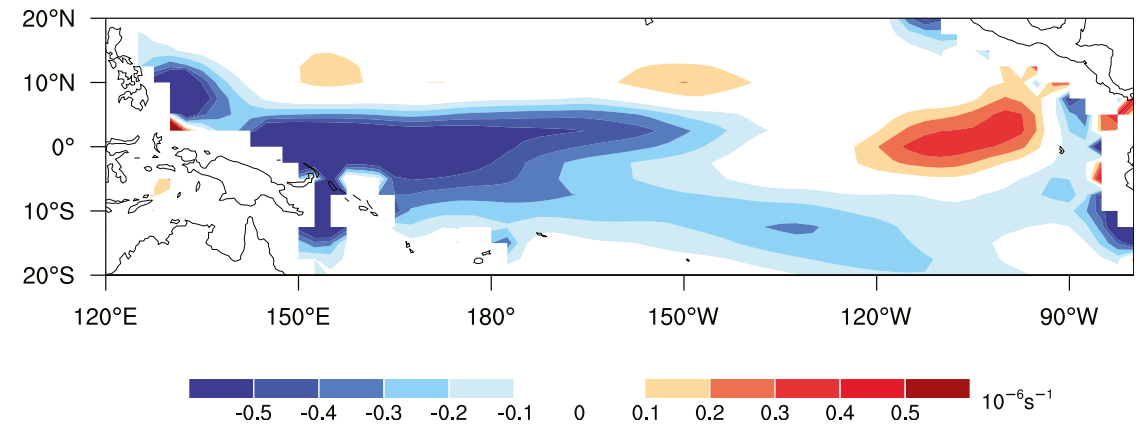

FIG. 10. (a) Zonal advection feedback in the MME of 25 CMIP5 models. (b) As in (a), but for the MME of 25 CMIP6 models. (c) Difference between (b) and (a). Stippling in (a) and (b) indicates the regions where the sign of the MME agrees in more than $68 \%$ of models.

scheme (Song and Zhang 2009), an underestimated negative shortwave-SST feedback (Bayr et al. 2018; Bayr et al. 2019b), a positive evaporation-SST feedback (Zhang and Song 2010), and an overly weak surface heating due to biases in the cloud cover (Sun et al. 2003). More studies undertake further investigation in the future.

Regarding the mechanism linking the CT strength and ENSO SST pattern in the models, the present study emphasizes the role of the oceanic dynamics and analyzes the effect of the atmospheric heat flux feedback, whereas some other factors, such as the effects of the positive wind-SST feedback, are not considered. Previous studies have found that the excessive CT could result in an underestimated positive wind-SST feedback and a weak negative shortwave feedback in CGCMs, which hampers the simulation of proper ENSO dynamics, asymmetry, and phase locking (Bayr et al. 2018, 2019b). This study suggests that the excessive CT could produce a zonal advection feedback bias through changing zonal SST gradient, leading to an excessive westward extension of ENSO SST pattern. The biased ocean-atmosphere coupling induced by the CT bias and its influence on the simulation of other ENSO parameters in CGCMs should be investigated in future.

Acknowledgments. We thank three anonymous reviewers for their constructive comments. This work was supported by the National Key Research and Development Program of China (2019YFA0606703), the National Natural Science Foundation of China (42005022, 41975116, 41831175, 91937302 and 41721004), the Key Deployment Project of Centre for Ocean Mega-Research of Science, Chinese Academy of 
Science (COMS2019Q03), the Youth Innovation Promotion Association of CAS (2016074), and the Natural Science Foundation of Jiangsu Province (BK20200532). The observed SST data used during this study are openly available from the Extended Reconstructed SST, version 3 (ERSST.v3), dataset at https://www.esrl.noaa.gov/psd/data/gridded/data.noaa.ersst.html as cited in Smith et al. (2008). The CMIP5 model datasets are available at https://esgf-node.llnl.gov/search/cmip5/. And the CMIP6 model datasets are publicly available at https://esgf-node.llnl.gov/ search/cmip6/.

\section{REFERENCES}

Bayr, T., M. Latif, D. Dommenget, C. Wengel, J. Harlass, and W. Park, 2018: Mean-state dependence of ENSO atmospheric feedbacks in climate models. Climate Dyn., 50, 3171-3194, https://doi.org/10.1007/s00382-017-3799-2.

- D. I. V. Domeisen, and C. Wengel, 2019a: The effect of the equatorial Pacific cold SST bias on simulated ENSO teleconnections to the North Pacific and California. Climate Dyn., 53, 3771-3789, https://doi.org/10.1007/s00382-019-04746-9.

_ C. Wengel, M. Latif, D. Dommenget, J. Lübbecke, and W. Park, 2019b: Error compensation of ENSO atmospheric feedbacks in climate models and its influence on simulated ENSO dynamics. Climate Dyn., 53, 155-172, https://doi.org/ 10.1007/s00382-018-4575-7.

Bellenger, H., E. Guilyardi, J. Leloup, M. Lengaigne, and J. Vialard, 2014: ENSO representation in climate models: From CMIP3 to CMIP5. Climate Dyn., 42, 1999-2018, https:// doi.org/10.1007/s00382-013-1783-z.

Cai, W., and Coauthors, 2015: ENSO and greenhouse warming. Nat. Climate Change, 5, 849-859, https://doi.org/10.1038/nclimate2743.

_ and Coauthors, 2018: Increased variability of eastern Pacific El Niño under greenhouse warming. Nature, 564, 201-206, https://doi.org/10.1038/s41586-018-0776-9.

Chen, L., T. Li, S. K. Behera, and T. Doi, 2016: Distinctive precursory air-sea signals between regular and super El Niños. Adv. Atmos. Sci., 33, 996-1004, https://doi.org/10.1007/s00376-016-5250-8.

Chowdary, J. S., A. Parekh, C. Gnanaseelan, and P. Sreenivas, 2014: Inter-decadal modulation of ENSO teleconnections to the Indian Ocean in a coupled model: Special emphasis on decay phase of El Niño. Global Planet. Change, 112, 33-40, https://doi.org/10.1016/j.gloplacha.2013.11.003.

Collins, M., and Coauthors, 2010: The impact of global warming on the tropical Pacific Ocean and El Niño. Nat. Geosci., 3, 391397, https://doi.org/10.1038/ngeo868.

Dwyer, J. G., M. Biasutti, and A. H. Sobel, 2012: Projected changes in the seasonal cycle of surface temperature. J. Climate, 25, 6359-6374, https://doi.org/10.1175/JCLI-D-11-00741.1.

Eyring, V., S. Bony, G. A. Meehl, C. A. Senior, B. Stevens, R. J. Stouffer, and K. E. Taylor, 2016: Overview of the Coupled Model Intercomparison Project Phase 6 (CMIP6) experimental design and organization. Geosci. Model Dev., 9, 19371958, https://doi.org/10.5194/gmd-9-1937-2016.

Ferrett, S., M. Collins, and H.-L. Ren, 2018: Diagnosing relationships between mean state biases and El Niño shortwave feedback in CMIP5 models. J. Climate, 31, 1315-1335, https:// doi.org/10.1175/JCLI-D-17-0331.1.

Gong, H., L. Wang, W. Chen, D. Nath, G. Huang, and W. Tao, 2015: Diverse influences of ENSO on the East Asian-western Pacific winter climate tied to different ENSO properties in CMIP5 models. J. Climate, 28, 2187-2202, https://doi.org/ 10.1175/JCLI-D-14-00405.1.
Graham, F. S., A. T. Winttenberg, J. N. Brown, S. J. Marsland, and N. J. Holbrook, 2017: Understanding the double peaked El Niño in coupled GCMs. Climate Dyn., 48, 2045-2063, https:// doi.org/10.1007/s00382-016-3189-1.

Guilyardi, E., and Coauthors, 2009: Understanding El Niño in ocean-atmosphere general circulation models: Progress and challenges. Bull. Amer. Meteor. Soc., 90, 325-340, https:// doi.org/10.1175/2008BAMS2387.1.

- H. Bellenger, M. Collins, S. Ferrett, W. Cai, and A. Wittenberg, 2012: A first look at ENSO in CMIP5. CLIVAR Exchanges, No 58, International CLIVAR Project Office, Southampton, United Kingdom, 29-32.

Ham, Y.-G., and J.-S. Kug, 2014: ENSO phase-locking to the boreal winter in CMIP3 and CMIP5 models. Climate Dyn., $\mathbf{4 3}$, 305-318, https://doi.org/10.1007/s00382-014-2064-1.

— , and — 2015: Improvement of ENSO simulation based on intermodel diversity. J. Climate, 28, 998-1015, https://doi.org/ 10.1175/JCLI-D-14-00376.1.

— S. Schubert, Y. Vikhliaev, and M. J. Suarez, 2014: An assessment of the ENSO forecast skill of GEOS-5 system. Climate Dyn., 43, 2415-2430, https://doi.org/10.1007/s00382014-2063-2.

Horel, J. D., and J. M. Wallace, 1982: Reply. Mon. Wea. Rev., 110, 1497, https://doi.org/10.1175/1520-0493(1982)110<1497:R>2.0.CO;2.

Huang, P., and S.-P. Xie, 2015: Mechanisms of change in ENSOinduced tropical Pacific rainfall variability in a warming climate. Nat. Geosci., 8, 922-926, https://doi.org/10.1038/ngeo2571.

Izumo, T., M. Lengaigne, J. Vialard, I. Suresh, and Y. Planton, 2019: On the physical interpretation of the lead relation between warm water volume and the El Niño Southern Oscillation. Climate Dyn., 52, 2923-2942, https://doi.org/ 10.1007/s00382-018-4313-1.

Jiang, W., G. Huang, K. Hu, R. Wu, H. Gong, X. Chen, and W. Tao, 2017: Diverse relationship between ENSO and the northwest Pacific summer climate among CMIP5 models: Dependence on the ENSO decay pace. J. Climate, 30, 109-127, https:// doi.org/10.1175/JCLI-D-16-0365.1.

_- P. Huang, G. Li, and G. Huang, 2020: Emergent constraint on the frequency of central Pacific El Niño under global warming by the equatorial Pacific cold tongue bias in CMIP5/6 models. Geophys. Res. Lett., 47, e2020GL089519, https://doi.org/ 10.1029/2020GL089519.

Jin, F.-F., S. T. Kim, and L. Bejarano, 2006: A coupled-stability index for ENSO. Geophys. Res. Lett., 33, L23708, https:// doi.org/10.1029/2006GL027221.

Johnson, N. C., and S. P. Xie, 2010: Changes in the sea surface temperature threshold for tropical convection. Nat. Geosci., $\mathbf{3}$, 842-845, https://doi.org/10.1038/ngeo1008.

Kim, S. T., and J.-Y. Yu, 2012: The two types of ENSO in CMIP5 models. Geophys. Res. Lett., 39, L11704, https://doi.org/ 10.1029/2012GL052006.

— W W. J. Cai, F.-F. Jin, and J.-Y. Yu, 2014: ENSO stability in coupled climate models and its association with mean state. Climate Dyn., 42, 3313-3321, https://doi.org/10.1007/s00382013-1833-6.

Kug, J.-S., Y.-G. Ham, J.-Y. Lee, and F.-F. Jin, 2012: Improved simulation of two types of El Niño in CMIP5 models. Environ. Res. Lett., 7, 034002, https://doi.org/10.1088/1748-9326/7/3/039502.

Latif, M., and N. S. Keenlyside, 2009: El Niño/Southern Oscillation response to global warming. Proc. Natl. Acad. Sci. USA, 106, 20 578-20 583, https://doi.org/10.1073/pnas.0710860105.

Lau, N. C., and M. J. Nath, 1996: The role of the "atmospheric bridge" in linking tropical Pacific ENSO events to extratropical 
SST anomalies. J. Climate, 9, 2036-2057, https://doi.org/10.1175/ 1520-0442(1996)009<2036:TROTBI>2.0.CO;2.

Li, G., and S.-P. Xie, 2012: Origins of tropical-wide SST biases in CMIP multi-model ensembles. Geophys. Res. Lett., 39, L22703, https://doi.org/10.1029/2012GL053777.

— , and —, 2014: Tropical biases in CMIP5 multimodel ensemble: The excessive equatorial Pacific cold tongue and double ITCZ problems. J. Climate, 27, 1765-1780, https:// doi.org/10.1175/JCLI-D-13-00337.1.

— tongue bias on the El Niño-northwest Pacific summer monsoon relationship in CMIP5 multi-model ensemble. Climate Dyn., 52, 6195-6212, https://doi.org/10.1007/s00382-018-4504-9.

Li, L., B. Wang, and G. J. Zhang, 2015: The role of moist processes in shortwave radiative feedback during ENSO in the CMIP5 models. J. Climate, 28, 9892-9908, https://doi.org/10.1175/ JCLI-D-15-0276.1.

Li, T., 1997: Phase transition of the El Niño-Southern Oscillation: A stationary SST mode. J. Atmos. Sci., 54, 2872-2887, https:// doi.org/10.1175/1520-0469(1997)054<2872:PTOTEN>2.0.CO;2.

Lloyd, J., E. Guilyardi, and H. Weller, 2011: The role of atmosphere feedbacks during ENSO in the CMIP3 models. Part II: Using AMIP runs to understand the heat flux feedback mechanisms. Climate Dyn., 37, 1271-1292, https://doi.org/ 10.1007/s00382-010-0895-y.

Misra, V., and Coauthors, 2007: Validating and understanding the ENSO simulation in two coupled climate models. Tellus, $\mathbf{5 9 A}$, 292-308, https://doi.org/10.1111/j.1600-0870.2007.00231.x.

Power, S., F. Delage, C. Chung, G. Kociuba, and K. Keay, 2013: Robust twenty-first-century projections of El Niño and related precipitation variability. Nature, 502, 541-545, https://doi.org/ 10.1038/nature12580.

Rasmusson, E. M., and T. H. Carpenter, 1982: Variations in tropical sea surface temperature and surface wind fields associated with the Southern Oscillation El Niño. Mon. Wea. Rev., 110, 354-384, https://doi.org/10.1175/1520-0493(1982)110<0354: VITSST $>2.0 . \mathrm{CO} ; 2$.

Ropelewski, C. F., and M. S. Halpert, 1987: Global and regional scale precipitation patterns associated with the El Niño/Southern
Oscillation. Mon. Wea. Rev., 115, 1606-1626, https://doi.org/ 10.1175/1520-0493(1987)115<1606:GARSPP>2.0.CO;2.

Smith, T. M., R. W. Reynolds, T. C. Peterson, and J. Lawrimore, 2008: Improvements to NOAA's historical merged landocean surface temperature analysis (1880-2006). J. Climate, 21, 2283-2296, https://doi.org/10.1175/2007JCLI2100.1.

Song, X., and G. J. Zhang, 2009: Convection parameterization, tropical Pacific double ITCZ, and upper-ocean biases in the NCAR CCSM3. Part I: Climatology and atmospheric feedback. J. Climate, 22, 4299-4315, https://doi.org/10.1175/ 2009JCLI2642.1.

Spencer, H., and J. M. Slingo, 2003: The simulation of peak and delayed ENSO teleconnections. J. Climate, 16, 1757-1774, https:// doi.org/10.1175/1520-0442(2003)016<1757:TSOPAD>2.0.CO;2.

Sun, D. Z., J. Fasullo, T. Zhang, and A. Roubicek, 2003: On the radiative and dynamical feedbacks over the equatorial Pacific cold tongue. J. Climate, 16, 2425-2432, https://doi.org/10.1175/ 2786.1.

Tao, W., G. Huang, R. Wu, K. Hu, P. Wang, and H. Gong, 2018: Origins of biases in CMIP5 models simulating northwest Pacific summertime atmospheric circulation anomalies during the decaying phase of ENSO. J. Climate, 31, 5707-5729, https://doi.org/10.1175/JCLI-D-17-0289.1.

Taylor, K. E., R. J. Stouffer, and G. A. Meehl, 2012: An overview of CMIP5 and the experiment design. Bull. Amer. Meteor. Soc., 93, 485-498, https://doi.org/10.1175/BAMS-D-11-00094.1.

Yeh, S. W., Y. G. Ham, and B. P. Kirtman, 2014: A possible explanation on the changes in the spatial structure of ENSO from CMIP3 to CMIP5. Geophys. Res. Lett., 41, 140-145, https://doi.org/10.1002/2013GL058478.

Zhang, G. J., and X. Song, 2010: Convection parameterization, tropical Pacific double ITCZ, and upper-ocean biases in the NCAR CCSM3. Part II: Coupled feedback and the role of ocean heat transport. J. Climate, 23, 800-812, https://doi.org/ 10.1175/2009JCLI3109.1.

Zheng, Y., J. Lin, and T. Shinoda, 2012: The equatorial Pacific cold tongue simulated by IPCC AR4 coupled GCMs: Upper ocean heat budget and feedback analysis. J. Geophys. Res., 117, C05024, https://doi.org/10.1029/2011JC007746. 